\title{
Hybrid Power Control System
}

\author{
Henry Oghenemine D., Fredrick Ilogho, Oladipo Folorunso \\ Department of Electrical Electronic Engineering, Afe Babalola University, Ado-Ekiti, Ekiti State, Nigeria \\ Corresponding Author: * Oladipo Folorunso
}

\begin{abstract}
A Hybrid Power Control System (HPCS) that gives out a single output has been designed to enable the automatic operation and transfer of power supply from three sources (public utility supply, photovoltaic system and ac generator). The Hybrid Power Control System provides a functional system that provides an automatic switching of power supply between the primary source (public utility) and two alternative sources (photovoltaic system and generator). The method employed in designing the HPCS involves the use of contactors, ATMEGA16L microcontroller, relay and motor drivers as part of the major components in the design. Also incorporated in the HPCS is a $12 \mathrm{Vdc}$ and a $5 \mathrm{Vdc}$ power supply unit, optocouplers and a liquid crystal display (LCD) for displaying the status of the HPCS at any particular time. The hybrid power control system demonstrates its ability to perform automatic power change over activities with no human interaction.
\end{abstract}

Keywords: Hybrid Power Control System (HPCS), Automatic Transfer Switch (ATS), relays, contactors.

\section{INTRODUCTION}

Industrial and commercial processes are dependent on electric power supply. Electricity supply instability in developing countries creates a need for alternative sources of power (to back up the utility supply) and the automation of electrical power generation (Ahmed et al., 2006). In Nigeria, power is far from stable which calls for frequent use of alternative sources of power. The introduction of these alternative sources of supply brings forth the challenge of switching smoothly and timely between the mains supply and the alternative sources, whenever there is a power interruption on the mains source. While the era of fluctuation and failure in supply of electricity is long forgotten in many industrialized nations of the world, many developing countries still suffer setbacks arising from incessant power failures. The provision of alternative power source (photovoltaic systems and generators) has no doubt brought sustenance but not without the constant manual change of the sources to the load. Hence the need for an hybrid power control system (HPCS). If the processes of changeover are manual, time is wasted; mal-operation and equipment damage can also result from overloading at changeover. The step loading feature helps in the protection of the generator coils, thereby increasing the life span of the generator, ensuring continuous flow of power and reducing machine downtime. In order to eliminate downtime (when downtime cannot be tolerated from power outage), an automatic changeover is required (Anant, 2016). In view of the inherent features of the switching device, this paper presents the design and construction of an automatic changeover for an hybrid system, which switches electrical power supply from public supply to photovoltaic system and then to generator when the mains supply is not still available. The system uses an electronic control circuit involving integrated circuits, transistors and electromechanical devices. The generator delay will help protect both the generating set and the appliances; a delay circuit allows the generator to run to full load, before connecting the load to it. The power indicator on the other hand gives the operator both visual and audio indication, when the public power is restored thereby reducing cost of power as it is cheaper to run on public power supply. This paper combines twin functions of automatic changeover and sequential (gradual or step) loading to eliminate the need for manual changeover, protect the loads, extend the lifespan of the generator and improve reliability of power supply. The importance of automatic change over and step loader cannot be over emphasized especially in critical industries like banking, telecommunications, defence, and healthcare where continuous operation is critical and interruption of power supply has grievous consequences. A sequential loader is used to ensure power gets to every load step by step. This is to ensure that power supply to the load is not accompanied by overloading of the generator. This device is designed to eliminate the common problem of overloading the generator during changeover (manual/automatic), which reduces the life span of the generator. In this project, an electronic control monitors the incoming public supply voltage and detects when the voltage drops below a level when electrical or electronic gadgets can function depending on the utility supply. In this case $160 \mathrm{~V}$ is the limit at which the system switches from public supply to alternative power source (photovoltaic system) and then to generator and 
vice-versa. There are basically three types of changeover switches based on the design and mode of operation namely: manual changeover, electrical changeover and electronic changeover. Manual changeover is the most popular changeover switch in use. Manual change-over switch consists of a manual change over switch box, switch gear box and cut-out fuse or the connector fuse (Rockis \& Mazur, 2001). This change-over switch box separates the source between the generator and public supply (Ahmed et al, 2006. The contact is manually switched from mains terminal to the generator terminal and vice-versa. The major drawbacks are that firstly, it requires a lot of human action to operate and also the ceramic insulator can crack during switching and lead to electric shock if the contact wire touches the metal casing. Secondly, it has led to several deaths and damage to electrical appliances (Uchenna et al., 2015). Rapid wear and tear of the mechanical parts also occurs due to continuous up and down movement which will lead to increased frequent maintenance eliminated because the control circuit shuts down and transfers the load to the alternative power supply (Nwafor et al., 2012). Electrical change over uses A.C. relay for its operation. It is also referred to as an Automatic Transfer Switch (HPCS) and is designed to enable the automatic operation and transfer of power supply between a public utility supply and an alternative power source. The HPCS, which is a switchgear control system, provides a functional system that provides an automatic switching of power supply between a primary source (public utility) and a secondary power source (photovoltaic system and generator). The methods employed in designing the HPCS involve the use of electromechanical type relays, contactors, voltage monitoring relays and delay timer relays as main components of the system Agbetuyi et al., 2011. The circuit does not require a deck power pack or controlling board. The advantage of this circuit is that it is cheap and easily constructed. The drawbacks include noise associated with switching of relays, wear and tear, arching which can cause fire outbreak, high component count making the system more prone to failures (Nwafor et al., 2012). Also, at low mains voltage, the a.c. relay and some contactors start chattering causing the output to be oscillating and this is dangerous to equipment connected to the output. Electronic changeover solves the shortcoming of the a.c. relay/contactor based changeovers. Two common approaches can be used. Solid state thyristors and opto-triac can be used for the switching or d.c relay (powered from a transformer power pack, whose stabilised voltage work to the desired value recommended) could be used. The chattering associated with relay and contactors is eliminated because the control circuit shuts down and starts the generator to supply power to the load. The relays are switched on and off by a transistor biased as a switch. The electronic changeovers are of two types. The first type does not have a time delay, which means it changes over immediately when the mains voltage is gone. But the generator starter has a periodic delay to start the generator. After starting, the feedback circuit from the generator helps deactivate the control circuit. The second method has a delay before it changes over. The delay keeps the generator running, until the mains voltage is present for say 1 to 5 minutes before switching off the generator. This method is still very good, but the only drawback is the fuel consumed during the delay time, hence it is hardly used in design because it is not cost effective (Kolo, 2007). The automatic change over switch has the following advantages (Uchenna et al., 2015);

a) It minimizes damages to lives/equipment since it has its own monitoring system and its switching requires no human contact with the switch, thus eliminating human error.

b) It reduces its change over timing to the minimum due to its fast response to power outage.

c) It maintains high quality of service through its fast and prompt response. The automatic change-over switch can be used in any place where alternative power is needed to complement the main power supply.

In this paper, photovoltaic system and generator set are used to represent the alternative power supplies. The generator to be used with the device should have the following features.

a. The generator must have electrical 'start and stop' facility.

b. The generator's battery has to be in good condition always.

c. The inter-connecting cables must be in good order (Ezema et al., 2012). 
II. METHODOLOGY

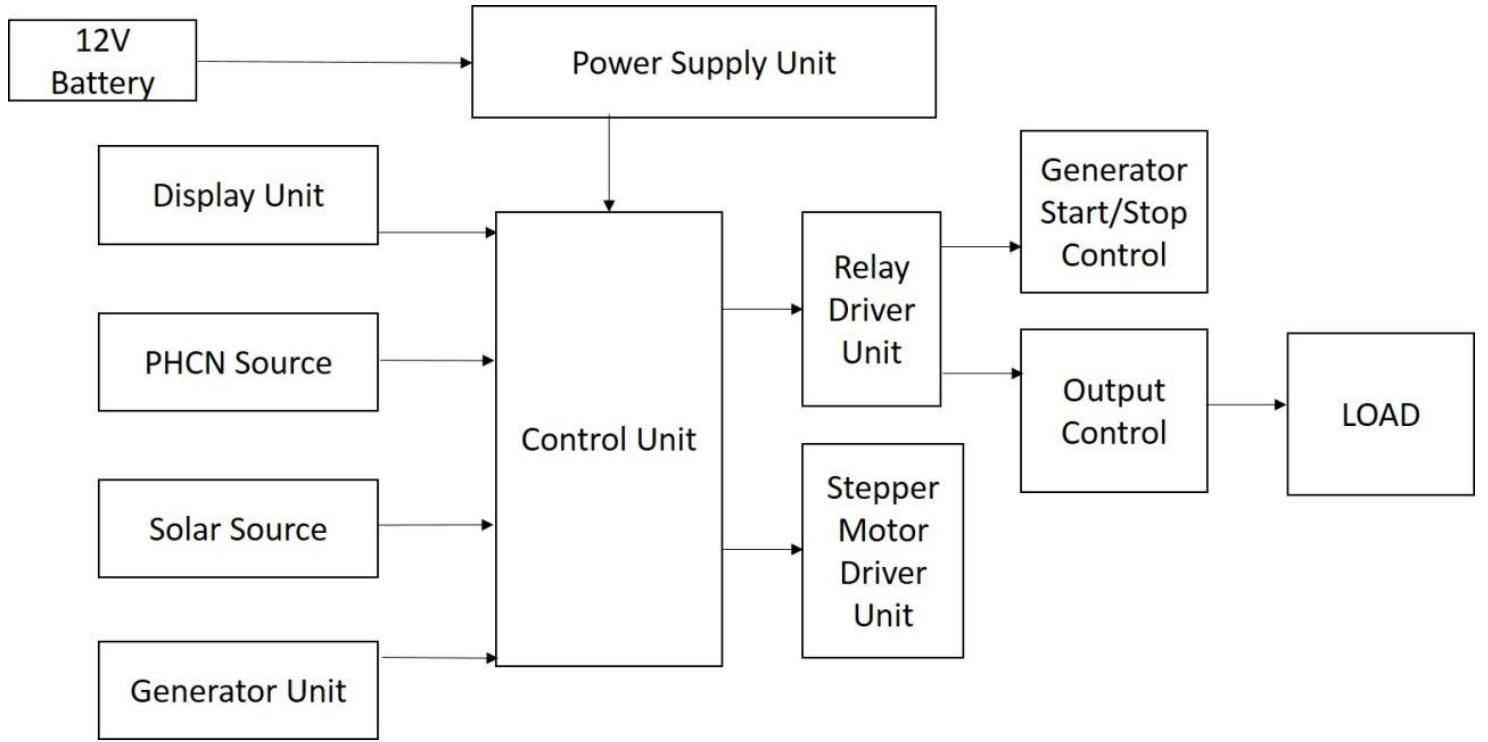

Figure 1: Block diagram showing the working principle of a hybrid power control system

The various units involved are as follows:

I. Power supply unit (12V battery, smoothing capacitor and the voltage regulator).

II. Power supplies (Mains Utility, Photovoltaic System, Generator)

III. Visual display unit (LCD)

IV. Load control (contactors)

V. Microcontroller circuit

The power supply unit consists of $12 \mathrm{~V}$ battery, smoothing capacitor and voltage regulator. It supplies $12 \mathrm{~V}$ needed to power the relays. The $12 \mathrm{~V}$ input also undergoes voltage regulation and is smoothened by smoothing capacitor to give an output of $5 \mathrm{~V}$ that serves as the supply for the microcontroller and LCD.

The microcontroller unit circuit is the heart of the project. This is where the program for the control part of the project is written and burned using assembly language and a universal programmer, respectively. The control unit also contains drivers for the relay and stepper motor.

The sequence of operation of the circuit is as follows

a. The circuit sequence is such that at turn on, it initialises the LCD.

b. Then, it checks to see if mains supply is available, if not, the circuit checks the battery level of the photovoltaic system and switches the load to it.

c. If after the sequence, the battery of the inverter is low (at 15\%), the circuit de-energises the photovoltaic contactor,

d. Then it activates the generator start sequence and energises the generator contactor.

e. If the generator is available, the load is supplied with generator and waits for mains supply to come back on.

f. If the mains supply comes on when the circuit is running on generator, it activates the generator stop sequence,

g. De-energises the generator contactor, energises the mains supply contactor and loads the circuit on mains supply,

h. Then turns off the generator (fan) after a delay sequence

i. On the other hand, if mains supply is available, it turns on the mains supply relay and waits till mains supply fails.

j. And the process repeats itself 


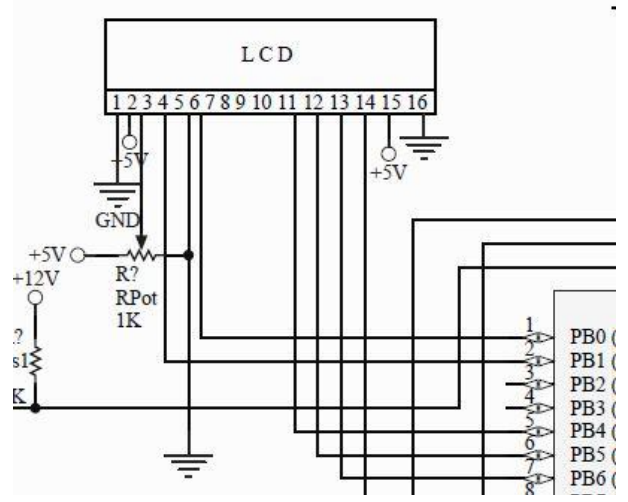

Figure 2: LCD connected to the microcontroller

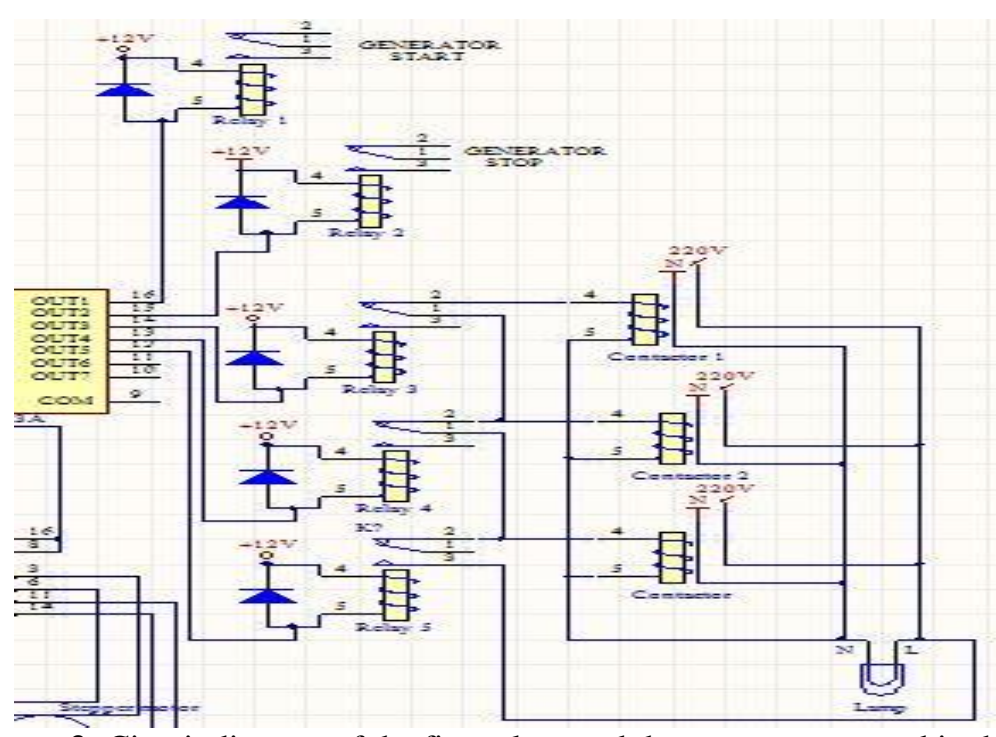

Figure 3: Circuit diagram of the five relays and three contactors used in this design

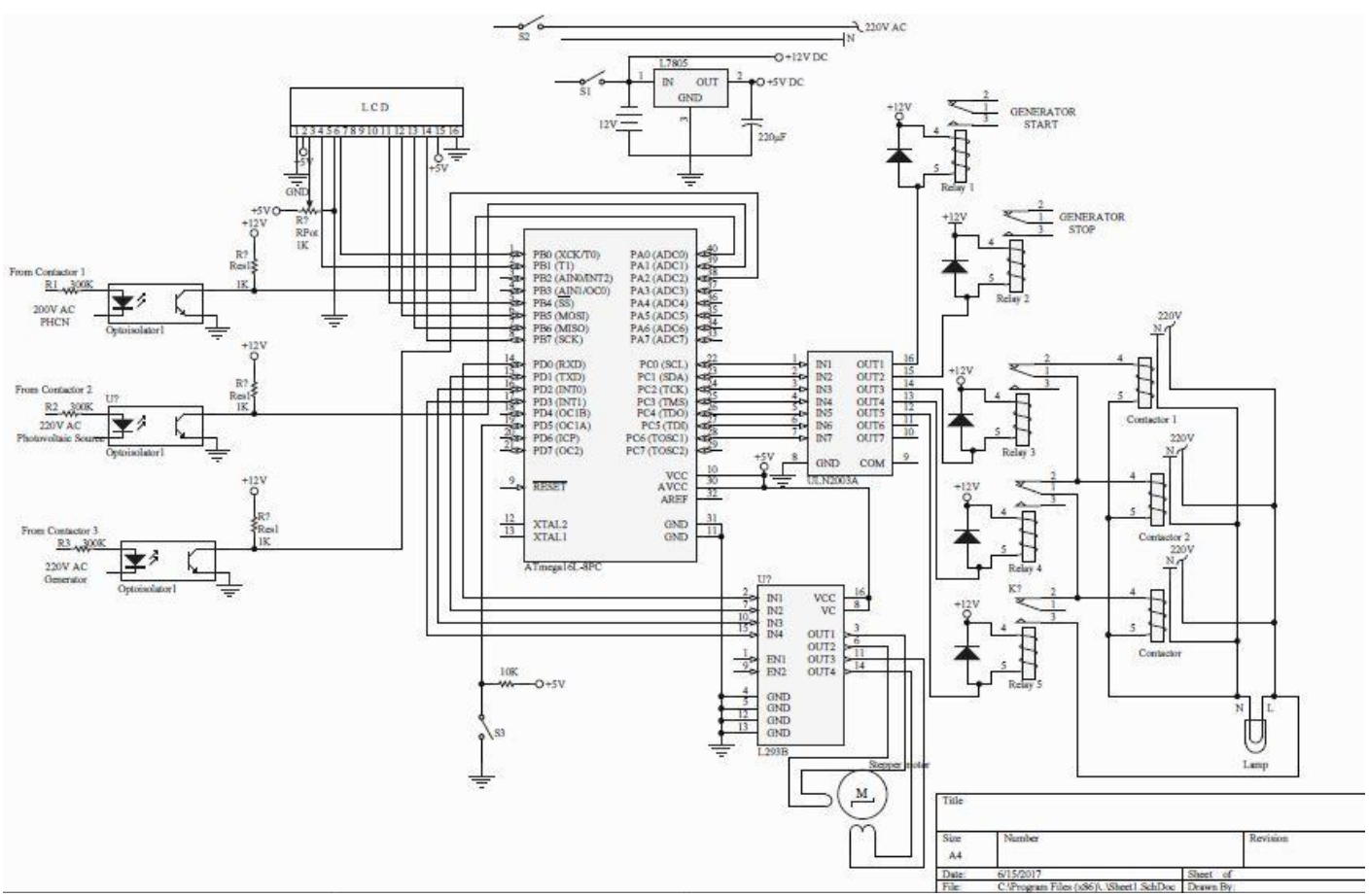

Figure 4: Circuit diagram showing the design and construction of a hybrid power control system 


\section{PERFORMANCE EVALUATION}

In order to test the performance of the system, contactor $\mathrm{M}$ is the contactor controlling the mains supply, contactor $\mathrm{P}$ is the contactor controlling the photovoltaic source, contactor $\mathrm{G}$ is the contactor controlling the generator source, switch $\mathrm{O}$ is the reset switch. A $60 \mathrm{~W}$ bulb is used as the load (though the circuit can power a complete building, and that was the reason why contactor was chosen) and a 12 Volts battery is used to supply the Power Supply Unit of the circuit.

The following steps were involved in the operation of the circuit:

a. Contactor M de-energized (OFF) simulates mains supply outage.

b. Contactor P de-energized (OFF) simulates photovoltaic supply outage.

c. Contactor $\mathrm{G}$ de-energized (OFF) simulates unavailability of generator source.

d. Contactor $\mathrm{M}$ energized (ON) simulates mains supply availability.

e. Contactor P energized $(\mathrm{ON})$ simulates photovoltaic supply availability.

f. Contactor $\mathrm{G}$ energized $(\mathrm{ON})$ simulates generator source availability.

g. Switch $\mathrm{O}$ opened (OFF) simulates only mains supply at any time.

h. Switch O closed (ON) simulates normal HPCS operation.

i. Bulb ON means the $60 \mathrm{~W}$ bulb lights by any of the three source

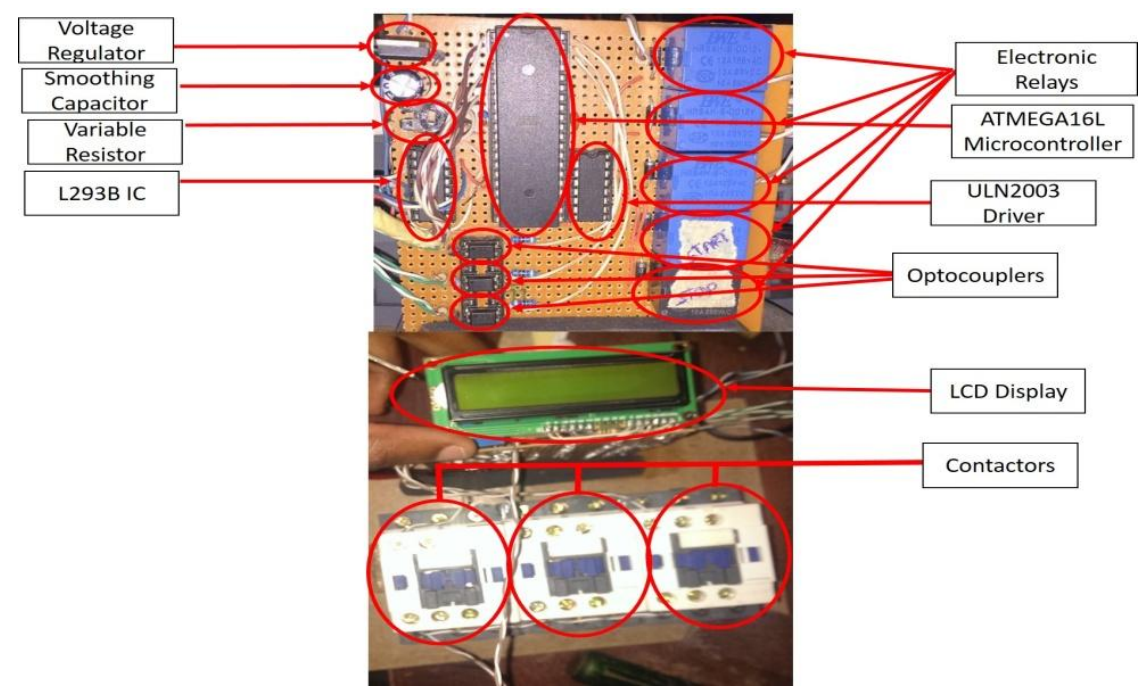

Figure 5: Completed circuit of the hybrid power control system

Table 1: Summary of performance evaluation

\begin{tabular}{|l|l|l|l|l|l|l|}
\hline Steps & $\begin{array}{l}\text { Contactor } \\
\text { M }\end{array}$ & $\begin{array}{l}\text { Contactor } \\
\mathrm{P}\end{array}$ & $\begin{array}{l}\text { Contactor } \\
\mathrm{G}\end{array}$ & $\begin{array}{l}\text { Switch } \\
\mathrm{O}\end{array}$ & Bulb & Comments/ Observations \\
\hline 1 & ON & OFF & OFF & ON & ON & $\begin{array}{l}\text { When there is supply in mains, the } \\
\text { photovoltaic and generator are OFF and } \\
\text { the load would be powered. }\end{array}$ \\
\hline 2 & OFF & ON & OFF & ON & ON & $\begin{array}{l}\text { When there is absence of mains, } \\
\text { photovoltaic source is turned ON. } \\
\text { Generator remains OFF and load would } \\
\text { be powered. }\end{array}$ \\
\hline 3 & OFF & OFF & ON & ON & ON & $\begin{array}{l}\text { When there is absence of both mains and } \\
\text { photovoltaic source, there is a delay of } \\
\text { 4secs before the generator comes ON and } \\
\text { the load would be powered. }\end{array}$ \\
\hline 5 & ON & ON & OFF & ON & ON & $\begin{array}{l}\text { When there is both mains and } \\
\text { photovoltaic source }\end{array}$ \\
\hline 6 & OFF & OFF & OFF & OFF & OFF & $\begin{array}{l}\text { OFFen Switch O is OFF and there is } \\
\text { abence of mains supply, the load would } \\
\text { not be powered. }\end{array}$ \\
\hline
\end{tabular}




\section{CONCLUSION}

The device was analyzed and tested. Based on the test results, the whole system performed according to the designed aim and objectives of the project. The hybrid power control system (HPCS) circuit was able to switch between the three power supply sources according to the set priority and also automatically switch on the generator and switch it off.

The device has been proven to be reliable and can be deployed in houses, offices, industrial settings and all environments where constant power supply is of great importance. With improved rating of the solar system and generator, more percentage of loads can be placed on them.

The present system is an improvement to both automatic and manual power change over.

\section{REFERENCES}

[1]. Agbetuyi, A. F., Adewale, A. A., Ogunluyi, J. O., \& Ogunleye, D. S. (2011). Design and Construction of an Automatic Transfer Switch for a Single Phase Power Generator. International Journal of Scientific and Engineering Research, 2(May), 1-8.

[2]. Ahmed, M. S., Mohammed, A. S., \& Agusiobo, O. B. (2006). Development of a Single Phase Automatic Change Over Switch. AU Journal of Technicial Report, 10(1), 68-74.

[3]. Amuzuvi, C. K., \& Addo, E. (2015). A Microcontroller Based Automatic Transfer Switching System for a Standby Electric Generator. Ghana Mining Journal, 15(1), 85-92.

[4]. Brown, B., Guditis, J., Critical, S. D., \& Competency, P. (2006). Critical-Power Automatic Transfer Systems - Design and Application. IEEE Central TN Section, 1(August), 1-18.

[5]. C, E. K., Uchenna, N., Henry, O. kelechi, \& Amaka, E. (2015). Microcontroller Based Power ChangeOver Switching System With Generator Shutdown. Journal of Multidisciplinary Engineering Science and Technology, 2(8), 2184-2189.

[6]. Christian, M. (2012). Smart Phase Change-over system with AT89C52 Microcontroller. Journal of Electrical and Electronics Engineering, 1(3), 31-34.

[7]. Chukwuemeka, C., Babajide, O., John, O., Agidani, J., \& Onyedikachi, V. (2015). Design and Implementation of Microcontroller Based Programmable Power Changeover. Computer Engineering and Intelligent Systems, 6(12), 51-56.

[8]. Ezema, L. S., Peter, B. U., Harris, O. O., \& Power, E. (2012). Design of Automatic Change Over Switch With Generator Control Mechanism. Natural Anf Applied Sciences, 3(3), 125-130.

[9]. Kolo, J. G. (2007). Design and Construction of an Automatic Power Changeover Switch. AU Journal of Technicial Report, 11(2), 1-6.

[10]. Okome, O., \& Oladipo, F. (2015). AUTOMATIC TRANSFER SWITCH WITH THREE PHASE SELECTOR.docx. International Journal of Scientific and Engineering Research, 6(7), 81-87.

[11]. Osaretin, C. A., Ibhadode, E. I., \& Igbinovia, S. O. (2016). DESIGN AND IMPLEMENTATION OF AUTOMATIC CHANGEOVER SWITCH ( WITH STEP LOADING ) FOR 